\title{
Vector bionomics, potential vectors and insecticide efficacy in malaria endemic areas, Ye Township, Mon State Myanmar
}

\author{
Maung Maung Mya*, Sein Thaung*, Nyan Sint**, Yee Yee Myint, Sai Zaw Min Oo*, Pae Phyo Kyaw*, Di \\ Lone*** and Yan Naung Maung Maung* \\ *Medical Entomology Research Division. \\ **Programme Manager VBDC, Mon State. \\ *** MI,VBDC, Ye Township Hospital, Mon State. \\ DOI: $10.31364 /$ SCIRJ/v8.i7.2020.P0720784 \\ http://dx.doi.org/10.31364/SCIRJ/v8.i7.2020.P0720784
}

\begin{abstract}
Vector bionomic and evaluation of insecticide efficacy were carried out in Koe Mine, Man Aung and 14 Mine areas of Ye Township, Mon State from July 2018 to August 2019 for better understanding of the Anopheles species distribution current insecticide susceptibility status and potential vector of malaria. Mosquitoes were collected using cattle baited net and light traps and larval survey was conducted in water well using WHO dipper. Standard WHO insecticide susceptibility was employed using field collected specimens. Results revealed that all total of 684 and 89 Anopheles mosquitoes consisted of 9 and 5 specie were collected from Koe Mine and Man Aung villages. Main vector An. minimus (6.58\% \& 3.37\%) and Secondary vector An. maculatus (52.34\%\&37.08\%) was collected in high density, An. philippinensis and An. jamesii adult was observed low density in both areas. Other species of An. willmori, An. annularis, An. kochi and An. aconitus were collected in Koe Mine village. All collected Anopheles mosquitoes were found sporozoite negative. These mosquitoes were also collected in indoor, outdoor and cow shed morning resting collected in low density. Susceptibility status of all collected Anopheles were found susceptible to WHO recommended insecticides. Although main vector of An. minius and secondary vectors of Anopheles were available in the villages moreover there is also filarial vector Culex quinquefasciatus mosquitoes larvae were observed high density and co breeder with An. minimus larvae and also DHF vector Aedes aegypti, Ae. albopictus and a new species of Ae. cogilli were also breeding in some water wells. There is high risk for the transmission of malaria, filarial and DF/DHF in both study areas, if diseases carrier is available in the villages and need to proper control measure as use of insecticide treated bed nets and application of focal residual spray for adults as well as treatment of abate or larvivorus fishes in water wells for larvae control to prevent vector borne diseases transmission in these areas.
\end{abstract}

Key words: Vector, bionomics, breeding habit, domestic water wells, An.minimus, Ae. aegypti, Ae.albopictus, Ae. cogilli, Cx. quinquefasciatus

\section{Introduction}

Previously malaria is one of the major public health problems in Myanmar. Malaria cases and death reduced by $62 \%$ and $91 \%$ in 2015 compared to 2012. The incidence of malaria is fall down by 49\% from 2012 to 2015 and no reported malaria outbreaks since $2012^{1}$. The malaria morbidity and mortality is still remaining in border and hard to reach areas. Primary and secondary vectors of malaria are still found in malaria free and endemic areas in the country. It is still a main contributor to the morbidity and mortality in some part of the country. In malaria prevention and control, use of insecticide treated bed nets and application of focal residual spray at selected areas are important part of the programme in endemic regions. An. dirus and An. minimus are major vectors of malaria in forested and forested foot hill areas of the country and An. annularis is a local vector of malaria in Rakhine State. An. sundaicus and An. subpictus are abundantly found in coastal areas of Rakhine, Mon and Tanintharyi Regions. The transmission of

Www.scirj.org

(C) 2020, Scientific Research Journal

http://dx.doi.org/10.31364/SCIRJ/v8.i7.2020.P0720784

This publication is licensed under Creative Commons Attribution CC BY. 
malaria is largely influenced by the abundance, survival and bionomics of the mosquito vectors ${ }^{2,3}$. The main vector control tools, long-lasting insecticidal nets (LLINs) and indoor residual spraying (IRS) at focal areas can be very effective in reducing malaria transmission. They are more effective against vectors which bite indoors (endophagic), late in the night (nocturnal) and which rest indoors after feeding (endophilic) ${ }^{4}$. These characteristics are observed for the primary malaria vector like An. minimus and are contributing to the success of the malaria control programmes in this region. However, it might be possible that after widespread and long-term insecticide exposure, the feeding and resting behaviour of vectors may become much more variable. Furthermore, vector mosquitoes may develop tolerance and leading to Pyrethroid resistance in endemic areas ${ }^{5}$. At the same time, residual effectiveness of the Insecticide treated bed net (ITN) and IRS should be monitored periodically for judicious use of insecticides and sustainable vector control $^{6}$. The operational criterion of resistance has usually been taken as the survival of $20 \%$ or more of the individuals tested at the currently known diagnostic concentrations using WHO test kits in field ${ }^{7}$. Therefore, updating and better understanding of the bionomics of vector mosquitoes are required together with monitoring of the insecticide susceptibility status and measuring of the residual effectiveness of insecticide treated surfaces at malaria endemic regions. It is essential to detect efficacy of currently used insecticides in the country and available information will be useful to complement the control programme. Present study planned to investigate the bionomics of malaria vectors and evaluate the efficacy of insecticides for strengthening of control strategies.

\section{Rationale}

Justification for the study site selection

Ye is a town in the southern end of Mon State. It is the principal town of the Ye Township of Mawlamyine District. Large and forested areas with over 40 villages are situated in the Township. The Township is the border area of the Thaninthayi Region and inhabited by 263624 people in $2721 \mathrm{Km}^{2}$ areas. Population density is $96.90 / \mathrm{km}^{2}$ as well as the economically it is most popular. The Township is situated in South part of the Thanbyuzayat Township, Mon State. Many creeks traverse the mainland and Ye river running across the Township as it drains into the Gulf of the Martaban and is surrounded by Thaninthayi hills in the east. The climate is tropical $\left(24^{\circ}\right.$ to $30^{\circ} \mathrm{C}$ temperature) and humid (mean relative humidity of $78.5 \%$ ) with abundant rainfall, supporting luxuriant and rich vegetation. In raining and cold seasons monthly new malaria cases were found in Ye Township and 1-2 malaria patients from Ye Township were admitted to Mawlamyaine General Hospital monthly (Personal communication).

Mon State is a malaria endemic area and primary and secondary vectors are abundantly present in this area ${ }^{2}$ and larvae of main vector An. dirus are abundantly found in domestic water wells ${ }^{8}$. According to the ecological changes, distribution of malaria morbidity patterns and results from the micro-stratification, the high risk areas for the malaria was about $38.90 \%$ in the 1990 was reduced to $17.00 \%$ in 2013. And free areas in the country were increased from $8.60 \%$ in 1990 to $37 \%$ in $2013^{9}$. Large numbers of native and migrant workers are working in rubber plantation and handmade factory's and contracted sites and they have needed to protect from vector borne diseases. Monthly malaria cases were found in Ye Township (Personal communication). There is a lack of data and information about the vectors, potential vectors and insecticide efficacy on Anopheles mosquito vectors in Ye Township, Mon State. Therefore an attempt has been made to determine the vector bionomics, potential vectors and insecticide efficacy of primary and secondary vectors of malaria in these areas.

\section{Materials and Methods}

Study area: Two villages as Koe Mine and Man Aung were selected in Ye Township, Mon State.

Study period: The study period was one year, stated from July 2018 to August 2019.

$$
\text { www.scirj.org }
$$


Mosquito's population: all collected mosquitoes and larvae in different collection methods such as cattle bait and light traps for adult collection and WHO dipper.

\section{Study areas}

Koe Mine and Man Aung villages were selected for adult Anopheles mosquitoes and larvae collection because malaria cases occurred annually according to hospital report. In Koe Mine village a total of on about 2730 population were stayed in 380 houses and in Man Aung village a total of 1070 population were lived in130 houses. These villages are at least 10 kilo meter away from Ye Township. All most all of the villagers are worked in Rubber and battle nut plantation in hilly areas. Same were school teacher, health workers and government staff. Ye-Dawe road is across to the Koe Mane village and Man Aung village is $10 \mathrm{Km}$ far away from Koe Mine village. And also want to know the distribution of malaria vector Anopheles mosquitoes in both villages.

\section{Methodology}

\section{Data collection procedures}

\section{Entomological Survey:}

\section{Mosquito collection}

Fixed mosquito catching stations were chosen in both selected villages. Indoor, outdoor light traps and animal bait catches were conducted in both areas in June. All catching stations were fixed in villages throughout the study periods.

Animal bite mosquito collection was done with big mosquito net (Kanda net=K net) and indoors and outdoors mosquito catching were done with CDC light traps method and mosquitoes were caught with WHO sucking tubes from 18:00 to 06:00 hours of the next day for 7days.

Indoor resting density: Mosquitoes resting place were searched in indoor and outdoor of the households and cowshed by the permission of householders in early in the morning and density was measured by the formula of Resting Density = total number of resting mosquitoes / total number of house checked. Indoor resting density $=$ total number of resting mosquitoes indoor / total number of houses checked indoor.

\section{$\underline{\text { Larval surveys }}$}

For identification of breeding sites larval surveys were conducted in and around three kilo-meters away from the study villages. Water pools, domestic wells, stream/creeks and all different types of water holding places were examined by 3 Dips /water holding place for larval detection ${ }^{10}$. In and around the villages, water pockets, coconut shells, discarded tins and utensils bamboo stumps including foot print of animals were examined. The captured larvae and pupae were put in labeled plastic bags and brought back to the laboratory for species identification and colonization.

Identification of adult Anopheles mosquitoes

Collected adult Anopheles mosquitoes and adult emerged from larva survey were identified by species according to different keys ${ }^{11-}$ 13 .

\section{Insecticide susceptibility test}

Insecticide susceptibility tests (WHO test kit):

Collected adult female Anopheles mosquitoes from the entomological survey were tested for measurement of insecticide susceptibility level using WHO test kits ${ }^{7}$ and standard procedures. The efficacy of insecticides which are commonly used for malaria 
vector control in malaria endemic areas namely as DDT4\%, Permethrin 0.75\%, Cyfluthrin $0.15 \%$ and Deltamethrin $0.05 \%$ impregnated paper with WHO test kits were provided.

Procedure

5 to10 fields collected Anopheles mosquitoes were introduced in WHO insecticide impregnated paper attached plastic tube (WHO test kit) by sucking tube and exposed for 1 hour. After one hour of exposing the mosquitoes were then removed from the plastic tubes and placed in clean plastic tubes without paper with $10 \%$ glucose soaked cotton and moisture were maintained by water soak dump towel. Percentage of knockdown was measured after 60 minutes exposure and effective mortality was assessed after 24 hours exposure. Two replicate testing were done to confirm the susceptibility of mosquitoes. If the quantity of collected mosquitoes was not more than 10 while we used pool mosquitoes samples to test insecticides susceptibility.

\section{Incrimination of vector}

Head and Thorax of vector mosquitoes were dissected for Plasmodium sporozoites. Enzyme Linked Immunosorbent assay (ELISA) test for circumsporozoite antigen detection was supplemented according to Wirtz et al., ${ }^{14}$ for vector incrimination study.

\section{Map of the study areas}

Map of the study areas, adult Anopheles mosquito collection sites, (indoor, outdoor and animal bait) larva positive places and human settlement areas were drawn by using Global Positioning System GPS (GPSMap16 Garman, 18x-5HZ software interface application ) method by expert person.

\section{Data analysis:}

Entomological data were analyzed and compared both study areas. Data entry, processing and analysis were carried out using Microsoft Excel software. Mosquitoes and larva density were determined in percentage. Insecticide susceptibility, potential vector were determine in percentage.

\section{Results}

Table 1: Occurrence of adult Anopheles mosquitoes in Koe Mine and Man Aung village Ye Township

\begin{tabular}{|l|l|l|l|c|c|c|c|}
\hline \multirow{2}{*}{ Sr.No. } & \multirow{2}{*}{ Species } & \multicolumn{4}{l|}{ Koe Mine village } & \multicolumn{3}{l|}{ Man Aung village } \\
\cline { 3 - 8 } & & $\begin{array}{l}\text { Collected } \\
\text { mosquitoes }\end{array}$ & $\begin{array}{l}\text { Density } \\
\%\end{array}$ & $\begin{array}{l}\text { Sporozoite } \\
\text { positivity }\end{array}$ & $\begin{array}{l}\text { Collected } \\
\text { mosquitoes }\end{array}$ & $\begin{array}{l}\text { Density } \\
\%\end{array}$ & $\begin{array}{l}\text { Sporozoite } \\
\text { positivity }\end{array}$ \\
\hline 1 & An. minimus & 45 & 6.58 & $\mathrm{Neg}$ & 3 & 3.37 & $\mathrm{Neg}$ \\
\hline 2 & An. maculatus & 358 & 52.34 & $\mathrm{Neg}$ & 33 & 37.08 & $\mathrm{Neg}$ \\
\hline 3 & An. jamesii & 27 & 3.95 & $\mathrm{Neg}$ & 27 & 30.34 & $\mathrm{Neg}$ \\
\hline 4 & An. willmori & 33 & 4.83 & $\mathrm{Neg}$ & 0 & 0 & $\mathrm{Neg}$ \\
\hline 5 & An. annularis & 47 & 6.87 & $\mathrm{Neg}$ & 0 & 0 & $\mathrm{Neg}$ \\
\hline 6 & An. kochi & 37 & 5.41 & $\mathrm{Neg}$ & 0 & 0 & $\mathrm{Neg}$ \\
\hline 7 & An. aconitus & 19 & 2.78 & $\mathrm{Neg}$ & 0 & $\mathrm{Neg}$ \\
\hline 8 & An. philippinensis & 31 & 4.53 & $\mathrm{Neg}$ & 17 & 19.10 & $\mathrm{Neg}$ \\
\hline 9 & An. barbirostris & 81 & 11.84 & $\mathrm{Neg}$ & 9 & 10.12 & $\mathrm{Neg}$ \\
\hline 10 & & 684 & 100 & $\mathrm{Neg}$ & 89 & 100 & $\mathrm{Neg}$ \\
\hline
\end{tabular}

Table 1. shows that total of 684 Anopheles mosquitoes consist of 9 Anopheles species and 89 adult Anopheles mosquitoes consist of 5 Anopheles species were collected from both Kow Mine and Man Aung villages. Main vector of An. minimus were collected in both Koe mine 45(6.58\%) and Man Aung village 3 (3.37\%). In Koe Mine village highest density of An. maculatus 52.34\% were collected followed by An. barbirostris $11.84 \%$ lowest was observed An. aconitus 2.78\%. In Man Aung village highest density of An. maculatus

www.scirj.org

(C) 2020, Scientific Research Journal

http://dx.doi.org/10.31364/SCIRJ/v8.i7.2020.P0720784

This publication is licensed under Creative Commons Attribution CC BY. 
$37.08 \%$ were collected followed by An. jamesii $30.34 \%$ and the lowest density was found An. minimus $3.37 \%$. Vector incrimination study found that all collected head and thorax of Anopheles mosquitoes were found sporozoite negative.

Table 2. Morning resting mosquito collection in indoor, outdoor and cowshed in Koe Mine and Man Aung villages in Ye Township

\begin{tabular}{|c|c|c|c|c|c|c|c|}
\hline \multirow[t]{2}{*}{$\begin{array}{l}\text { Sr. } \\
\text { No. }\end{array}$} & & \multicolumn{3}{|c|}{$\begin{array}{l}\text { Koe Mine village ( } 5 \text { days morning resting } \\
\text { collection) }\end{array}$} & \multicolumn{3}{|c|}{$\begin{array}{c}\text { Man Aung village (5 days morning } \\
\text { resting collection) }\end{array}$} \\
\hline & & Indoor & Outdoor & Cow shed & Indoor & Outdoor & Cow shed \\
\hline \multirow[t]{8}{*}{1} & An. minimus & $2 \pm 0.54$ & $1 \pm 0.45$ & $5 \pm 0.71$ & $1 \pm 0.45$ & $0 \pm 0.00$ & $2 \pm 0.54$ \\
\hline & An. maculatus & $6 \pm 0.45$ & $2 \pm 0.54$ & $13 \pm 1.14$ & $4 \pm 0.84$ & $4 \pm 0.84$ & $12 \pm 1.14$ \\
\hline & An. kochi & $2 \pm 0.54$ & $1 \pm 0.45$ & $5 \pm 0.71$ & 0 & 0 & 0 \\
\hline & An.jamesii & 0 & 0 & 0 & $3 \pm 0.55$ & $3 \pm 0.89$ & $6 \pm 0.84$ \\
\hline & An. philippinensis & 0 & 0 & $3 \pm 0.71$ & 0 & 0 & $1 \pm 0.71$ \\
\hline & An. annularis & $5 \pm 0.71$ & $1 \pm 0.45$ & $4 \pm 0.84$ & $3 \pm 0.89$ & $1 \pm 0.45$ & $3 \pm 1.34$ \\
\hline & Culex & $19 \pm 1.64$ & $3 \pm 0.89$ & $37 \pm 1.94$ & $19 \pm 1.09$ & $9 \pm 0.1 .30$ & $54 \pm 2.78$ \\
\hline & Total & $34 \pm 7.05$ & $8 \pm 0.89$ & $67 \pm 13.15$ & $30 \pm 7.35$ & $17 \pm 3.51$ & $78 \pm 20.47$ \\
\hline
\end{tabular}

Table 2. shows that highest number of mosquitoes were collected from cowshed in both areas i.e. $67 \pm 13.15$ and $78 \pm 20.47$ followed by $34 \pm 7.05$ and $30 \pm 7.35$ from indoor and lowest were observed in outdoor of both Koe Mine and Man Aung villages. Of this six species of Anopheles mosquitoes were collected. The highest number of An. maculatus was collected $13 \pm 1.14$ in koe mine and $12 \pm 1.14$ from Man Aung villages in cowshed morning resting collection. Main vector An. minimus was collected higher $5 \pm 0.71$ and $2 \pm 0.54$ from cowshed than indoor $2 \pm 0.54$ and $1 \pm 0.45$ resting morning collection in both Koe Mine and Man Aung villages. Culex mosquitoes were found higher in all indoor $(19 \pm 1.64,19 \pm 1.09)$ outdoor $(3 \pm 0.89,9 \pm 0.1 .30)$ and cowsheds $(37 \pm 1.94,54 \pm 2.78)$ in both areas.

Table 3. Breeding habitats of different mosquito species in Koe Mine, Man Aung and 14 Mine (Ma Hlew Taung villages in Ye Township Mon State

\begin{tabular}{|c|c|c|c|c|c|c|c|c|c|c|}
\hline \multirow{2}{*}{$\begin{array}{l}\text { Sr. } \\
\text { No. }\end{array}$} & \multirow{2}{*}{ Collected mosquito larvae } & \multicolumn{3}{|c|}{ Koe Mine } & \multicolumn{3}{|c|}{ Man Aung } & \multicolumn{3}{|c|}{14 mine (Ma Hlew Taung) } \\
\hline & & $\begin{array}{c}\begin{array}{c}\text { Total } \\
\text { examined } \\
\text { well }\end{array} \\
72\end{array}$ & 49 & 68.05 & $\begin{array}{c}\begin{array}{c}\text { Total } \\
\text { examined } \\
\text { well }\end{array} \\
25\end{array}$ & 19 & 76.00 & $\begin{array}{c}\text { Total } \\
\text { examined } \\
\text { place in } \\
\text { creek }\end{array}$ & 13 & 41.93 \\
\hline 2 & An. minimus & & 6 & 12.25 & & 3 & 15.79 & 3 & 3 & 23.08 \\
\hline 4 & Ae.aegypti+Ae.albopictus & & 0 & 0 & & 1 & 5.26 & & 0 & 0 \\
\hline & Ae.cogilli & & 0 & 0 & & 1 & 5.26 & & 0 & 0 \\
\hline 5 & Cx.quinq +An.mini) & & 3 & 6.12 & & 2 & 10.53 & & 0 & 0 \\
\hline & Cx.quinq + An.mini + Taxo) & & 0 & 0 & & 1 & 5.26 & & 0 & 0 \\
\hline 6 & An.maculatus & & 0 & 0 & & 0 & 0 & 5 & 10 & 76.92 \\
\hline
\end{tabular}

Cx.quinq =Cx.quinquefasciatus, An.mini=An.minimus, Taxo= Toxorhynchities

Table 2. Shows that detail breeding habit of Anopheles, Culex and Aedes larvae in water wells and creeks in study areas in Yee Township. A total of 72 and 25 wells were examined and found that 49 (68.05\%) and 19 (76.00\%) wells were positive for mosquitoes larvae in Koe Mine and Man Aung village. Highest number of Cx. quinquefasciatus habitats (Water wells) were found in Koe Mine village 40(81.63\%) followed by 11(57.90\%) in Man Aung village. Anopheles minimus larvae were breed 6(12.25\%) and 3(15.79\%) wells in Koe Mine and Man Aung villages. In both villages Cx.quinquefasciatus and An. minimus larvae were bred together in $3(6.12 \%)$ wells in Koe Mine and 2(10.53\%) wells in Man Aung. Only 2(10.53\%) wells from Man Aung village were found Aedes

www.scirj.org

(C) 2020, Scientific Research Journal

http://dx.doi.org/10.31364/SCIRJ/v8.i7.2020.P0720784

This publication is licensed under Creative Commons Attribution CC BY. 
larvae positivity. Of this one well was found Aedes aegypti and Ae. albopictus larvae and another well was positive with Ae. cogilli. In 14 Mine (Ma Hlew Taung =Ma Hlew hill) area larval survey was done in 31 places in creek of the Ma Hlew Taung, and found that $3(23.08 \%)$ of the An. minimus habitats and 10(76.93\%) of the An.maculatus breeding habitats were found beside the creek where the water is slowly running.

Table 4. Susceptibility and sporozoite positivity status of collected Anopheles mosquitoes from Koe Mine and Man Aung villages in Ye Township

\begin{tabular}{|c|c|c|c|c|c|c|}
\hline \multirow[t]{3}{*}{ Sr.No. } & \multirow[t]{3}{*}{ Species } & \multirow[t]{3}{*}{ samples } & \multicolumn{2}{|l|}{ Susceptibility test } & \multirow{2}{*}{\multicolumn{2}{|c|}{$\begin{array}{l}\text { Sporozoite } \\
\text { detection by ELISA }\end{array}$}} \\
\hline & & & \multirow{2}{*}{$\begin{array}{l}\text { impregnated } \\
\text { (WHO) }\end{array}$} & \multirow[t]{2}{*}{ Results } & & \\
\hline & & & & & Test samples & $\begin{array}{l}\text { Sporozoite } \\
\text { positivity }\end{array}$ \\
\hline $\begin{array}{l}\text { Koe } \\
\text { Mine } \\
\text { village }\end{array}$ & $\begin{array}{l}\text { An. minimus } \\
\text { An. maculatus } \\
\text { An. jamesii } \\
\text { An. willmori } \\
\text { An. annularis } \\
\text { An. kochi } \\
\text { An. aconitus } \\
\text { An. philippinensis } \\
\text { An. barbirostris }\end{array}$ & $\begin{array}{l}40 \\
80 \\
20 \\
20 \\
40 \\
20 \\
19 \\
20 \\
40\end{array}$ & $\begin{array}{l}\text { DDT4\%, } \\
\text { Permethrin } 0.75 \% \text {, } \\
\text { Cyfluthrin } 0.15 \% \\
\text { Deltamethrin } 0.05 \%\end{array}$ & Susceptible & $\begin{array}{l}45 \\
358 \\
27 \\
33 \\
47 \\
37 \\
19 \\
31 \\
81\end{array}$ & Negative \\
\hline $\begin{array}{l}\text { Man } \\
\text { Aung } \\
\text { village }\end{array}$ & $\begin{array}{l}\text { An. minimus } \\
\text { An. maculatus } \\
\text { An. jamesii } \\
\text { An. philippinensis } \\
\text { An. barbirostris }\end{array}$ & $\begin{array}{l}3 \\
33 \\
27 \\
17 \\
9\end{array}$ & $\begin{array}{lr}\text { DDT4\%, } & \\
\text { Permethrin } & 0.75 \% \text {, } \\
\text { Cyfluthrin } & 0.15 \% \\
\text { Deltamethrin } & 0.05 \%\end{array}$ & Susceptible & $\begin{array}{l}3 \\
33 \\
27 \\
17 \\
9\end{array}$ & Negative \\
\hline
\end{tabular}

Table 4. shows that all collected Anopheles mosquitoes from Koe Mine and Man Aung villages were highly susceptible to WHO recommended Insecticides as DDT4\%, Permethrin $0.75 \%$, Cyfluthrin $0.15 \%$ and Deltamethrin $0.05 \%$ as well as sporozoite positivity status of collected Anopheles mosquitoes were found sporozoite negative by ELISA test.

\section{Discussion}

Sporadic studies on different species of mosquitoes suggest ecological and biological differences in types of larval habitat, seasonality and behaviour according to species ${ }^{15-17}$ but such differences also occur for specific species within their distributions and could relate to key environmental factors. Variation in behaviour, such as early biting or ovipositing in wells, might determine vector capacity and adaptation to changing environment. Even so, Anopheles species exploit a variety of breeding habitats that vary considerably in size, altitude, vegetation cover and topography ${ }^{18-19}$.

Of the 37 Anopheline species recorded in Myanmar An.dirus and An.minimus are primary vector of malaria in Myanmar other local vector as An.annularis is a vector of malaria in Rakine State and An. sundigus and An. subpictus are the vector of costal areas as Taninthayi and Mon state ${ }^{2}$. In the present study occurrence of Anopheles mosquitoes in Ye township found that a total of 9 species of Anopheles mosquitoes were collected, the highest density of An. maculatus 358 (52.39\%) from Koe Mine and 33 (30.34\%) from Man Aung villages were collected followed by An. barbirostris 81(11.84\%) in Koe Mine and An. jamesii 27(30.34\%) in Man Aung by cattle bate k-net collection within 5 days. Although the main vector An. minimus was collected 45(6.58\%) in Koe mine and 3(3.37\%) in Man Aung village were lower density when compared with the secondary vector An maculatus. Similarly high density of An.minimus and An.maculatus were observed from Katinehtit and Kinedaw villages Kamamaung Township Kayin State and An.

Www.scirj.org

(C) 2020, Scientific Research Journal

http://dx.doi.org/10.31364/SCIRJ/v8.i7.2020.P0720784

This publication is licensed under Creative Commons Attribution CC BY. 
minimus and An.dirus were found potential vector of malaria in this area ${ }^{20}$. In the present study main vector An. dirus have not collected in both areas although monsoon is starting. Other researchers observed that high density of An. dirus were collected in monsoon period in Yephyu Township Taninthayi, Oktwin Township Bago Regions and low density was observed in Kamamaung Township Kayin State ${ }^{21-23}$. Study carried out in different areas reported that An.dirus and An.minimus are the major vectors of malaria although An. culicifacies, An.vagus, Anmaculatus, An.annularis and An. philipinansis are the secondary or suspected vectors in Myanmar'. Anopheles dirus, An.minimus, An.philippinensis, An.culicifacies, An. stiphensi, An. fluviatelis are vector of malaria in India $^{24}$, and An. culicifacies B and $\mathrm{E}$ are present in India and Sri Lanka ${ }^{25,26}$. In the present study main vector An.minimus was found highly active from $21.00 \mathrm{hr}$ to $24.00 \mathrm{hr}$ in outdoor in both Koe Mine and Man Aung village and pick biting time was found between 22:00 and $23.00 \mathrm{hr}$. Although Thailand researchers revealed that An. minimus showed biting activity at 19:00-21:00 hr indoors and again at 19:00-20:00 hr and 23:00-00:00 hr in outdoors ${ }^{27}$. In a previous study in western Thailand, the main biting activity of $A n$. minimus was indoors between 01:00 and 04:00 with a peak at 02:00, whereas outdoor feeding started around 22:00, reaching a peak near midnight ${ }^{27}$. Recently, Kwansomboon et al., ${ }^{29}$ reported that An. minimus fed preferentially outdoors along the Thailand-Myanmar border (0.57 and 0.58 ). Maculatus group consisted essentially of An. rampae which is highly zoophilic ${ }^{30}$ and has no confirmed role in malaria transmission ${ }^{30,31}$. Same finding was observed in present studied An. maculatus was abundantly collected from cattle bate collection and they are suspected vector of malaria in Myanmar. In the present study all collected mosquitoes were found soprozoite negative by ELISA method. Although other researcher found that vector incrimination study of An. dirus, An. minimus, An. kochi and An. maculatus were sporozoite positive in Bubpin Township in Thaninthayi Region and An. minimus and An. culicifacies were found sporozoite positive in Ann Township, Rakhaine State Myanmar ${ }^{32}$. Maung Maung Mya and his associate reported that An. minimus was $P f$ circumsporozoite positive which was collected indoor at $11 \mathrm{pm}$ in Katine Htit village and one An. dirus was $P v_{210}$ circumsporozoite positive which was collected from outdoor human bait collection at 10:00pm in Kine Taw village Kamamaung Township, Kayin State Myanmar ${ }^{20}$.

Highest numbers of mosquitoes were collected from cowshed in both areas than indoor and outdoor mosquito collection in both Koe Mine and Man Aung villages. Of this six species of Anopheles mosquitoes were collected. The highest number of An. maculatus was collected in Koe mine and Man Aung villages in cowshed morning resting collection.

Main vector $A n$. minimus was collected higher in Koe Mine than Man Aung from cowshed resting morning collection. Anopheles mosquitoes were mostly collected under the hanging cloths and bomboo baskets as resting position. Culex mosquitoes were found higher in all indoor, outdoor and cowsheds in both areas and these mosquitoes were mostly found under the bed, cloths, baskets, open bags and moisture areas. Other researcher revealed that highest number of An.dirus mosquitoes were collected biting outdoor in May 1996 and 1997 in Ohnbinkwin village, Yephyu Township Taninthayi Region ${ }^{21}$.

Breeding habitats of different mosquito species in Koe Mine, Man Aung and 14 Mine (Ma Hlew Taung) villages in Ye Township Mon State were found An. minimus, Culex and Aedes larvae were bred in domestic water wells, no water wells were observed in 14 Mine (Ma Hlew Taung) village. A total of 72 and 25 wells were examined and found that $49(68.05 \%)$ and 19 (76.00\%) wells were positive for mosquitoes larvae in Koe Mine and Man Aung village. Almost all of the larval positive wells were found full of the vegetative on the surface of the wells and debris in water. Anopheles minimus larvae were breed 6(12.25\%) and 3(15.79\%) wells in Koe Mine and Man Aung villages. In both villages Cx.quinquefasciatus and An. minimus larvae were bred together in 3(6.12\%) wells in Koe Mine and 2(10.53\%) wells in Man Aung. Only 2(10.53\%) wells from Man Aung village were found Aedes larvae, one well was positive with Aedes aegypti and Ae. albopictus larvae and one well was found Ae. cogilli positivity. Highest number of Culex www.scirj.org

(C) 2020, Scientific Research Journal

http://dx.doi.org/10.31364/SCIRJ/v8.i7.2020.P0720784

This publication is licensed under Creative Commons Attribution CC BY. 
quinquefasciatus were breeding in wells 40(81.63\%) in Koe Mine village and 12(63.16\%) in Man Aung village. It is the first time report of the An.minimus, Ae.aegypti, Ae. albopictus, Ae.cogilli and Cx.quinquefasciatus larvae in water well in Myanmar. And also Ae. cogilli (new species) was first time found in Myanmar in Man Aung village from Ye Township Mon State. Although other researchers revealed that An. dirus larvae were highly breeding in water wells in Mon state and Taninthayi Region ${ }^{8,21}$ but they are deep forested breeding in rock pools ${ }^{22}$. Although Maung Maung Mya and his associate reported that An. dirus larvae were found in water wells and An.minimus larvae were found in sand pools and slowly running water in Kamamaung Township Kayin State in rainy season $^{20}$. In a coastal village, Chantaburi Province of Thailand near the Cambodian border, the breeding of An.dirus is in small watercollections (gam pits) ${ }^{33}$. Although in Thabewa village Oktwin Township Bago Region found An.dirus larvae were highly breed in rock pools in forested hilly area and An.minimus was observed in slowly running water in Thabewa creek and water pools near the $\mathrm{creek}^{22}$. The result are agreed with the present study it was found that 3(23.08\%) of the An. minimus habitats and $10(76.93 \%)$ of the An.maculatus breeding habitats were found beside the creek of Ma Hlew Taung where the water is slowly running. Pe Than Htun et al., found that An.minimus were abundantly present in rice fields ${ }^{34}$. Other researcher revealed that An.minimus were co breeder with An. culicifacies in sand pools in Pakkaung and Phyu Townships Bago Region and abundantly collected in slowly running water in Yunsalin creek of Kamamaung Township Kayin State ${ }^{35,23,20}$. Other researcher from India revealed that An. stephensi was bred in high temperature water $\left(35 \mathrm{~d} \mathrm{C}\right.$ ) in overhead tank and in wells water minimum $26.58{ }^{\circ} \mathrm{C}$ in December and maximam $28.59{ }^{\circ} \mathrm{C}$ in $\mathrm{May}{ }^{36}$. In both Koe mine and Man Aung villages $81.63 \%$ and $63.16 \%$ of the domestic wells were found Culex quinquefasciatus larvae in large numbers. The wells were found different in shape, size and depth. They were approximately 10 to 50 feet deep and some were circular and some were square in shape as well as some are muddy well covered with bamboo or woods and some are covered with break some were made large concrete pipes. Most of the wells were under shade of trees and Shelters. A researcher from India revealed that $66.67 \%$ of wells and $63.64 \%$ of other breeding habitats with An. stephensi breeding were observed to co-inhabit with either Culex or Aedes species. However, co-inhabitation of anophelines with other mosquito species in Over Head Tanks was rare (5 $\%)^{36}$. Farjana et al., ${ }^{37}$ revealed that drains were the most common aquatic habitat of Anopheles and Culex larvae in Boyra, Kewatkhali and Balashpur and Culex quinquefasciatus is widely distributed over all the localities, similar findings have been reported in Dhaka city ${ }^{38}$. The results were agreed with the abundant of Cx. quinquefasciatus larvae and co breeder of An. minimus larvae in both study areas. It may be due to the fact that in dry season mosquitoes breeding habitats are dried in both areas therefore polluted water bred $C x$. quinquefasciatus and slowly running water bred An. minimus may change their breeding habit and habitats to permanently remained wells water.

In the present study 2(10.53\%) of the domestic water wells were found Aedes larvae positivity. Of this $5.26 \%$ well was found Ae. aegypti and Ae. albopictus larvae. Other researchers revealed that certain Aedes species, as Ae. albopictus and Ae.aegypti are highly breed in artificial containers Car tyres, metal drums, plastic drums, Bago jars, earthen pots concrete jars in Myanmar ${ }^{22,39,40}$, tree holes and other variety of container in Northen Nigeria ${ }^{41}$. Certain Aedes species, including Ae. albopictus, are able to breed in artificial containers ${ }^{42}$. Aedes aegypti is an urban species, whereas An. albopictus prefers to breed in the rural conditions in breed both in artificial and natural containers ${ }^{43}$. In the present study, one of the water well in Man Aung village was observed Ae. cogilli larvae. This is the first time report of the Ae.cogilli in Myanmar in Man Aung village Ye Township Mon State. Same findings also found the first time has been recorded Aedes (Phagomyia) cogilli in Sri Lanka and morphologically confirmation and molecular characterization was supported the presence of Ae. cogilli as well as Ae. cogilli had developed resistance to common insecticides and developed adaptations to urban environment, raising health and environmental concerns and it was collected in the canals of the Jaffna Municipality area in Sri Lanka ${ }^{44}$. Other researchers revealed that Ae. cogilli is regarded as a sylvatic species mainly breeding in tree holes and hollow bamboos ${ }^{45}$. Although in the present study found Ae. cogilli was bred in water well in Man Aung village. Ae. cogilli www.scirj.org

(C) 2020, Scientific Research Journal

http://dx.doi.org/10.31364/SCIRJ/v8.i7.2020.P0720784

This publication is licensed under Creative Commons Attribution CC BY. 
is a dominant species in India ${ }^{46}$. Aedes aegypti and $C x$. nebulosus showed highest preferences for breeding in automobile Tyres, $C x$. horridus and $C x$, quinquefqsciatus larvae occurred most in wells ${ }^{41}$. Other researcher reported that Aedes vittatus is currently found in Africa, Asia and Europe, where it acts as a vector of pathogens causing animal and human diseases and Ae. vittatus and Ae. cogilli, while similarities with other, public databases provided a $\geq 99 \%$ similarity with sequences for two Aedes mosquitoes ${ }^{42}$ (Fernández et al., 2018). Larvae of Ae. vittatus have been recorded in a variety of habitats including rock pools, tree holes, domestic containers and hoofprints $^{47,48}$

World Health Organization estimated that $40 \%$ of the 506 insect species of medical importance had evidence of resistance to various insecticides ${ }^{2}$. Most documented cases of resistance have involved organochlorine, organophosphate, and carbamate class compounds compared with the relatively more recent introduction of broad-spectrum pyrethroids ${ }^{49}$. In present study found that all collected Anopheles mosquitoes from Koe Mine and Man Aung villages were highly susceptible to WHO recommended Insecticides as DDT4\%, Permethrin0.75\%, Cyfluthrin 0.15\% and Deltamethrin 0.05\%. Same insecticides susceptibility status of Anopheles mosquitoes collected from Pin Oo Lwin township Mandalay Region and Kamamaung Township Kayin state were found 100\% sensitivity to WHO recommended insecticides ${ }^{23}$. Although other researcher observed that An. dirus s.l. is susceptible to DDT ${ }^{50}$ but $^{-}$ due to exophilic behaviour, females avoid treated walls ${ }^{51}$ or even avoid the sprayed huts by biting more outdoors after residual spraying $^{52}$. An Indian researcher working on unwashed PermaNet in India found that 100\% mortality in both An. minimus and An. dirus $^{53}$. Anopheles dirus was found to have $100 \%$ knockdown and mortality against brand-new, one and three year duration of unwashed PermaNet 2.0 and very sensitive to deltamethrin treated different LLINs nets on An.minimus and secondary vector of malaria in different parts of Myanmar ${ }^{54,55}$. A Thailand researcher revealed that contact irritancy is a major behavioral response of both An. minimus $\mathrm{A}$ and $\mathrm{C}$ when exposed directly to any of the three compounds commonly used agricultural insecticides, carbaryl (carbamate), malathion (organophosphate) and cypermethrin (pyrethroid), whereas only cypermethrin produced a significant repellency response in An. minimus species $\mathrm{A}^{56}$. Although WHO report from 2010 to 2016 revealed that there was no clear indication of an overall global increase in resistance frequency to the other three insecticide classes commonly used in malaria vector control. However, increased resistance since 2010 was evident for the WHO South-East Asia Region for organochlorines (predominantly DDT) (12\% rise, from $17 \%$ to $29 \%$ ), carbamates (9\% rise, from $0 \%$ to $9 \%$ ) and organophosphates (11\% rise, from $1 \%$ to $12 \%$ ). There was also some evidence of an increase in organochlorine resistance frequency in the WHO Eastern Mediterranean Region since 2010 (9\% rise, from $24 \%$ to $33 \%$ ). The only increase in resistance frequency for nonpyrethroid insecticides identified for any African subregion was an increase in carbamate resistance in central Africa (6\% rise, from $6 \%$ to $12 \%)^{57}$.

In conclusion

Main vector An. minimus adult and larvae were collected in both Koe Mine and Man Aung villages and larvae were found in domestic water well in both areas and larvae of An. minimus and An.maculatus were collected in the Ma Hlew Taung creek of 14 Mine . Secondary vector An. maculatus was collected in high density, An. philippinensis and An.jamesii adult was observed low density in both areas. Other species of An. willmori An. annularis An. kochi and An. aconitus were collected in Koe Mine village. All these mosquitoes were also collected in indoor, outdoor and cow shed morning collected. Susceptibility status of all collected Anopheles were found susceptible to DDT4\%, Permethrin0.75\%, Cyfluthrin 0.15\% and Deltamethrin 0.05\%. Although main vector of An.minius and secondary vectors of An.minimus, An.philippinensis, An. jamesii, An.kochi, An. willmorri and An.annularis were available in villages moreover there is also filarial main vector of Culex quinquefasciatus mosquitoes larvae were observed high density in water wells and they are co breeder with Anopheles larvae and also DHF vector Aedes aegypti and Ae.albopictus and a new species of Ae.cogilli were breeding in water wells. Therefor there is a high risk for the transmission of malaria, filarial and DF/DHF in both www.scirj.org 
study areas need to proper control measure as use of insecticide treated bed nets and application of focal residual spray for adults as well as treatment of abate or larvivorus fishes in water wells for larvae control to protect vector borne diseases transmission in these areas. In prevention and control, at selected areas are important part of the programme in Ye township Mon State.

\section{References}

1. National Elimination Plan (2016-2030) vision Myanmar free from malaria by 2030. Goals interrupt transmission \& eliminate indigenous malaria by 2030 .

2. Khin Maung Kyi (1970) Malaria vectors in Burma Anopheles balabacensis balabacensis Baisas, 1936. Union Bur J. Life Sci., 3:217-225.

3. Maung Maung Mya, Myat Phone Kyaw, Sein Thaung, Tin Tin Aung and Yan Naung Maung Maung. Vector bionomics and potential vectors of malaria in Kamamaung Township, Phapun District, Kayin State. Programme and abstracts 44th Myanmar Health Research Congress 2016; p 77.

4. Yukich JO., Lengeler C., Tediosi F., Brown N., Mulligan JA., et al.,. Costs and consequences of large-scale vector control for malaria. Malaria Journal 2008; 7:258.

5. N'Guessan R, Corbel V, Akogbeto M, Rowland M: Reduced efficacy of insecticide-treated nets and indoor residual spraying for malaria control in pyrethroid resistance area, Benin. Emerg Infect Dis 2007; 13:199-206.

6. Corbel V, Chabi J, Dabiré Roch K, Etang J, Nwane P, Pigeon O, Akogbeto M, Hougard JM: Field efficacy of a new mosaic long-lasting mosquito net (PermaNet@ 3.0) against pyrethroid resistant malaria vectors: a multi centre study in Western and Central Africa. Malar J 2010; 9:113.

7. WHO . Vector resistance to pesticides: fifteenth Report of the WHO Expert Committee on Vector Biology and Control. WHO Tech Rep Ser 1992; 818.

8. Tun Lin W, Myo Paing and Zaw Myint. A modification of the WHO dipping procedure for well-breeding Anopheles in Burma. Trop. Biomed.1988; 5:51-55.

9. Health in Myanmar. Annual public health statistics, Ministry of Health. Health in Myanmar 2014.

10. World Health Organization. Manual on practical entomology in malaria part II. Geneva: WHO 1975.

11. Harrison B.A., (1980). Medical Entomology Studies: XIII. The Myzomyia series of Anopheles (Cellia) in Thailand, with emphasis on intra-interspecific variation (Diptera:Culicdae). Am Entomology Inst 17:1-195.

12. Raid, J.A. (1967). Two Forms of Anopheles philippinensis malago. J. Med. Entomol., 4: 175-179.

13. Myo Paing, Thi Thi Naing, Sein Min and Zaw Myint (1990b) Anopheles mosquitoes of Myanmar. III. Anopheles (Cellia) philippinensis Ludlow 1902 \& Anopheles (cellia) nivipes Thebald 1903 in Myanmar and their differentiating characters. Myanmar Health Sci. Res. J. 2:32-38.

14. Wirtz RA., Burkot TR., Graves PM., and Andre RG (1987) Field evaluation of Enzyme Link Immunosorbent assay for Plasmodium vivax sporozoites in mosquitoes (Diptera: Culicidae) in Papua New Guinea. Journal of Medical Entomology24:433-437.

15. Baimai V, Kijchalao U, Sawadwongporn P, Green CA: Geographic distribution and biting behaviour of four species of the Anopheles dirus complex (Diptera: Culicidae) in Thailand. Southeast Asian J Trop Med Pub Hlth 1988, 19:151-161.

www.scirj.org

(C) 2020, Scientific Research Journal

http://dx.doi.org/10.31364/SCIRJ/v8.i7.2020.P0720784

This publication is licensed under Creative Commons Attribution CC BY. 
16. Sallum MAM, Peyton EL, Wilkerson RC: Six new species of the Anopheles leucosphyrus group, reinterpretation of An. elegans and vector implications. Med Vet Entomol 2005, 19:158-199.

17. Rattanarithikul R, Green CA, Panyim S, Noigamol C, Chanaimongkol S, Mahapibul P: Larval habitats of malaria vectors and other Anopheles mosquitoes around a transmission focus in northwestern Thailand. J Am Mosq Control Assoc 1995, 11:428-433.

18. Peyton EL: A new classification for the leucosphyrus group of Anopheles (Cellia). Mosq Syst 1989, 21:197-205.

19 Rajavel AR, Das PK: A review of Leucosphyrus Group with particular reference to the Anopheles dirus complex (Diptera: Culicidae) in India. J Commun Dis 1998, 30:57-67.

20 Maung Maung Mya, Myat Phone Kyaw, Sein Thaung, Tin Tin Aung, and Yan Naung Maung Maung. Potential vectors of malaria in Kamamaung, Myanmar and their bionomic. Indian Journal of Entomology, 80 online published. IJE 17042/August, 2018 article DOI Number : 10.5958/0974-8172.00245.6. Indian Journal of Entomology, 2018; 80(4):1-8

21 Htay Aung, Sein Minn, Sein Thaung, Maung Maung Mya, Sein Maung Than, Thaung Hlaing Soe Soe and P. Druilhe Quecuche. Well breeding Anopheles dirus and their role in malaria transmission in Myanmar. South east Asian J. Trop Med Pub Health.1999; 30: 447-453.

22 Tun Lin W, Maung Maung Mya, Sein Maung Than and Tin Maung Maung. Rapid and efficient removal of immature Ae. aegypti in metal drums by sweep net and modified sweeping method. Southeast Asian J Trop Med Public Health 1995; 26(4) 754-759.

23 Maung Maung Mya, Myat Phone Kyaw, Sein Thaung, Tin Tin Aung and Yan Naung Maung Maung. Occurrence of Anopheles mosquitoes, potential vector, sibling species and susceptibility in malaria endemic areas of Kamamaung Township, Kayin State. Myanmar Health Sciences Research Journal 2017; 29(2):165-166.

24 Sharma VP. Current scenario of malaria in India. Parassitologia.1999 41(1-3), 349-353.

25 Subbarao SK, Anopheles sibling species complex in South-East Asia. New Delhi: WHO regional Offices for South-East Asia, 1998.

26 Surendran S.N., Abhayawardana T.A., De silva BGDNK, Ramasamy M.S. and Ramasamy R. Anopheles culicifacies Y chromosome dimorphism indicates the presence of sibling species (B and E) with different malaria vector potential in Sri Lanka. Medical Veterinary Entomology. 2000; 14:437-440.

27 Marasri N., Overgaard H.J., Sumarnrote A., Thanispong K., Corbel V., and Chareonviriyaphap T. Abundance and distribution of Anopheles mosquitoes in a malaria endemic area along the Thai-Lao border. Journal of Vector Ecology. 2017; 42(2):325-334.

28 Tisgratog, R., C. Tananchai, W. Juntarajumnong, S. Tuntakom, M.J. Bangs, V. Corbel, and T. Chareonviriyaphap. Host feeding patterns and preference of Anopheles minimus (Diptera: Culicidae) in a malaria endemic area of western Thailand: baseline site description. Parasit. Vectors. 2012; 5: 114.

29 Kwansomboon, N., V. Chaumeau, P. Kittiphanakun, D. Cerqueira, V. Corbel, and T. Chareonviriyaphap. Vector bionomics and malaria transmission along the Thailand-Myanmar border: a baseline entomological survey. J. Vector Ecol.2017; 42: 8493.

www.scirj.org

(C) 2020, Scientific Research Journal

http://dx.doi.org/10.31364/SCIRJ/v8.i7.2020.P0720784

This publication is licensed under Creative Commons Attribution CC BY. 
30 Somboon, P., D. Thongwat, and R.E. Harbach. 2011. Anopheles (Cellia) rampae n. sp., alias chromosomal form K of the Oriental Maculatus Group (Diptera: Culicidae) in Southeast Asia. Zootaxa. 2810: 47-55.

31 Singh, S., A. Prakash, R.N. Yadav, P.K. Mohapatra, N.P. Sarma, D.K. Sarma, J. Mahanta, and D.R. Bhattacharyya. Anopheles (Cellia) maculatus group: its spatial distribution and molecular characterization of member species in north-east India. Acta Trop.2014; 124: 62-70.

32 Saw Lwin, Sein Min and Maung Maung. Longitudinal study of vector bionomics of malaria in Rakhine State and Thaninthayi Region. Presentation in Entomology workshop on 9-10 February 2016.

33 Scanlon JE, Sandhinand U: The distribution and biology of Anopheles balabacensis in Thailand (Diptera: Culicidae). J Med Entomol 1965, 47:61-69.

34 Pe Than Tun, Yan Naung Maung Maung, Sein Min, Sein Thaung, Sai Zaw Min Oo and Maung Maung Mya. Vector surveillance and insecticide efficacy in malaria endemic areas. Myanmar Health Research Congress 2013; pp72-73.

35 Maung Maung Mya, Pe Than Htun, Sein Min and R.K. Saxena (2012) Cytotaxonomical Studies of Anopheles culicifacies complex and its malaria vectorial capacity in Myanmar. International Journal of Contemporary research in Engineering and Technology; 2(2):17-26.

36 Thomas1S., Ravishankaran S., Johnson A. J., Aswin A.,. Mathai M. T., Valecha N., Thomas M.B. and Eapen A., Overhead tank is the potential breeding habitat of Anopheles stephensi in an urban transmission setting of Chennai, India. Malaria Journal (2016) 15:274-283

37 Farjana T., Ahmmed M. S., Khanom T. F., Alam N. and Begum N. Surveillance of mosquitoes larva at selected areas of Mymensingh district in Bangladesh. Bangl. J. Vet. Med. (2015). 13 (1): 79-88.

38 Ahmed TU. Mosquito problem in Bangladesh with special emphasis on urban mosquito situation and its control. Key note presentation at the conference of the Entomological Society of Bangladesh, 1996; pp. 10- 25.

39 Maung Maung Mya, Myint Myint Chit, Saw Mitchell and Maung Maung Gyi and Tin Oo. Community-based control of Aedes aegypti larvae by using Toxorhynchites larvae in selected townships of Yangon Division, Myanmar. Myanmar Health Sciences Research Journal.2011; 23(2):pp101-107.

40 Nyunt Nyunt Oo, Maung Maung Mya, Myo Thandar Thone, Aye Thida Than, Nu Nu Aung and Yan Naung Maung Maung. Occurrence of Aedes larvae in domestic water storage containers in two villages of Pakokku Township Magway region, Myanmar. World Journal of Pharmaceutical and Life Sciences, 2019;. 5(7): 9-17.

41 Adebote A.D., Oniye J.S., Ndams S.I., Nache K.M., The breeding of mosquitoes (Diptera: Culicidae) in peridomestic containers and implication in Yellow Fever transmission in villages around Zaria, Noethern Nigeria. Journal of Entomology.2006 3(2):180-188.

42 Fernandez AD, Puente JM, Ruiz S, Lopez RG, Soriguer R, Figuerola J. Aedes vittatus in Spain: current distribution, barcoding characterization and potential role as a vector of human diseases. Parasites \& Vectors. 2018; 11:297.

43 Khan AM, Khan AQ, Dobrzynasky L, Joshi GP and Hung M. A Japanese encephalitis focus in Bangladesh. American Journal of Tropical Medicine and Hygiene 2018; 48: 41-44.

44 Jayadas,T.T.P., Thiruchenthooran V., Tharsan A., Sivabalakrishnan K., Santhirasekaram S., Karvannan K., and Surendran S. N. First record of the presence of Aedes (Phagomyia) cogilli (Edwards, 1922) in Sri Lanka: Naturally adapted to develop in an urban environment. Journal of Entomology and Zoology Studies 2019; 7(2): 930-932.

45 Barraud PJ. The fauna of British India, including Ceylon and Burma, Diptera, Family-Culicidae, Tribes-Megarhinini and Culicini. Taylor and Francis, London, 1933463.

www.scirj.org

(C) 2020, Scientific Research Journal

http://dx.doi.org/10.31364/SCIRJ/v8.i7.2020.P0720784

This publication is licensed under Creative Commons Attribution CC BY. 
46 Tyagi BK, Munirathinam A, Venkatesh A. A catalogue of Indian mosquitoes. International Journal of Mosquito Research. 2015; 2(2):50-97.

47 Service MW. Studies on the biology and taxonomy of Aedes (Stegomyia) vittatus (Bigot) (Diptera: Culicidae) in Northern Nigeria. Ecol Entomol. 1970; 122:101-43.

48 Bueno-Marí R, Jiménez-Peydró R. Revision and new data on Aedes vittatus (Bigot, 1861) for Spain (Diptera: Culicidae). Dugesiana. 2010;17:143-4.

49 Brogdon WG, McAllister JC. Simplification of adult mosquito bioassays through use of time-mortality determinations in glass bottles. J Am Mosq Control Assoc.1998; 14: 159-164.

50 Trung HD: Malaria vectors in Southeast Asia: identification, malaria transmission, behaviour and control, PhD Prince Leopold Institute of Tropical Medicine Antwerp, Department of Parasitology, University of Antwerp, Faculty of Sciences, Department of Biology; 2003.

51 Cheong WH, Warren M, Omar AH, Mahadevan S: Anopheles balabacensis balabacensis identified as vector of simian malaria in Malaysia. Science 1965, 150:1314-1315.

52 Suwonkerd W, Ung B, Rimwangtrakul K, Wongkattiyakul S, Kattiyamongkool B, Chitprarop U, Takagi M: A field study on the response of Anopheles dirus to DDT and Fenitrothion sprayed to huts on Petchabun Province, Thailand. Trop Med 1990, 32:1-5.

53 Prakash A., Bhattacharyya DR., Mohapatra PK., Gogoi P., Sarma DK. Bhattacharjee K and Mahanta J. Evaluation of permanet巴 2.0 mosquito Bednets against mosquitoes, including Anopheles minimus s.1., in India. Southeast Asian J Trop Med Public Health. 2009; 40 (3): 449-457.

54 Maung Maung Mya, Sein Thaung, Chit Thet Nwe, Yi Yi Myint ,Thu Zar Nyein Mu, Zar Zar Aung and Thaung Hlaing. Bioefficacy of Brand-new and Long -term used PermaNet 2.0 against Anopheles dirus, Aedes aegypti and Culex quinquefasciatus. Myanmar Health Sciences Research journal.2015; 27(1):28-35.

55 Maung Maung Mya*, Sein Thaung, Yee Yee Myint, Thu Zar Nyein Mu, Yan Naung Maung, Moh Moh Tun, Khin Saw Aye, Kyaw Zin Thant. Bio-efficacy of Long Lasting Insecticidal Mosquito Nets (LLINs) on Malaria Vector Anopheles Mosquitoes in Malaria-Endemic Areas of Myanmar. Journal of Biological Engineering Research and Review, 2019; 6(1): 21-28.

56 Pothikasikorn Jinrap, Han Overgaard, Chitap Ketavan, Surapo Visetson, Michael J. Bangs, and Theerapha Chareonviriyaphap. Behavioral Responses of Malaria Vectors, Anopheles minimus Complex, to Three Classes of Agrochemicals in Thailand. Journal of Medical Entomology, 2007; 44(6):1032-1039.

57 WHO, | WHO interim position statement - the role of larviciding for malaria control in sub-Saharan Africa. WHO Available at: http://www.who.int/malaria/publications/atoz/ larviciding_position_statement/en/. (Accessed: 25th October 2016).

WwW.scirj.org

(C) 2020, Scientific Research Journal

http://dx.doi.org/10.31364/SCIRJ/v8.i7.2020.P0720784

This publication is licensed under Creative Commons Attribution CC BY. 